\title{
Modelling the behaviour of circular footings under combined loading on loose carbonate sand
}

\author{
M. J. CASSIDY*, B. W. BYRNE† and G. T. HOULSBY†
}

\begin{abstract}
A work-hardening plasticity model for the behaviour of rigid circular footings on loose carbonate sand is described. The model incorporates vertical, moment and horizontal force resultants and the corresponding displacements of the footing, and allows predictions of response to be made for any load or displacement combination. The model is a modification of an existing work-hardening model for circular footings on dense silica sand (published by Houlsby and Cassidy, 2002) and is based on a series of specifically designed tests on loose carbonate sand (Byrne and Houlsby, 1998, 2001). Retrospective simulation of the experimental data verifies the model's suitability for use in this soil type and conditions.
\end{abstract}

KEYWORDS: calcareous soils; model tests; numerical modelling; offshore engineering; plasticity; soil/structure interaction
Nous décrivons un modèle de plasticité à écrouissage pour le comportement d'assises circulaires rigides sur du sable de carbonate meuble. Ce modèle comporte les résultantes de force verticale, de moment et horizontale et les déplacements correspondants des assises; il permet de prédire les réponses à apporter pour toute combinaison de charge ou de déplacement. Ce modèle est une modification d'un modèle à écrouissage existant pour des assises circulaires sur du sable siliceux dense (publié par Houlsby et Cassidy, 2002) et il s'appuie sur une série d'essais conçus spécifiquement pour du sable de carbonate meuble (Byrne et Houlsby, 1998, 2001). La simulation rétrospective des données expérimentales confirme que le modèle pourra être utilisé dans ce type de sol et ces conditions.

\section{INTRODUCTION}

Recently there has been considerable interest in the development of numerical models for shallow foundation behaviour based on plasticity theory. There have been a number of experimental investigations that have provided data necessary to support this approach. Most of this research has concentrated on dense silica sands (Schotmann, 1989; Tan, 1990; Nova \& Montrasio, 1991; Gottardi \& Butterfield, 1993, 1995; Gottardi et al., 1999; Byrne, 2000; Houlsby \& Cassidy, 2002) and clays with increasing strength with depth (Martin \& Houlsby, 2000, 2001). This approach has also been investigated for shallow footings on uncemented loose carbonate sand by Byrne \& Houlsby (2001). They used a series of tests to verify the suitability of plasticity theory when applied to foundation response on this diverse material. The purpose of this paper is to outline a work-hardening plasticity model that describes the behaviour of a circular foundation on uncemented loose carbonate sand when subjected to drained combined loading. The model is based on the experimental data of Byrne \& Houlsby (1998, 2001).

An existing strain-hardening plasticity model for circular footings on dense silica sand forms the framework of this work. In this model, which is described in Houlsby \& Cassidy (2002) and known as Model C, any combination of load or deformation path can be applied to the footing and the corresponding unknowns (deformations or loads) can be calculated. It has been found to be applicable to loose carbonate sands. In this paper we outline the minor modifications necessary for Model $\mathrm{C}$ to be confidently applied to modelling circular foundations on carbonate sand. These

Manuscript received 10 May 2002; revised manuscript accepted 16 September 2002.

Discussion on this paper closes 1 June 2003, for further details see p. ii.

* Centre for Offshore Foundation Systems, the University of Western Australia.

$\dagger$ Department of Engineering Science, Oxford University. include a new hardening expression, yield surface expansion due to horizontal and rotational plastic displacements (as well as vertical), and revised values of the existing Model C parameters for application in loose carbonate sand.

\section{DETAILS OF THE MODEL}

The equations used to formulate the modified model are presented here. A more detailed explanation of Model $\mathrm{C}$ is given in Houlsby \& Cassidy (2002) and Cassidy (1999). The sign convention used is that suggested by Butterfield et al. (1997), and is shown in Fig. 1. Definition of the Model C parameters and recommended values for loose carbonate sand are provided in Table 1. The model has four major components:

(a) An empirical expression for the yield surface in threedimensional vertical, normalised moment and horizontal loading space:

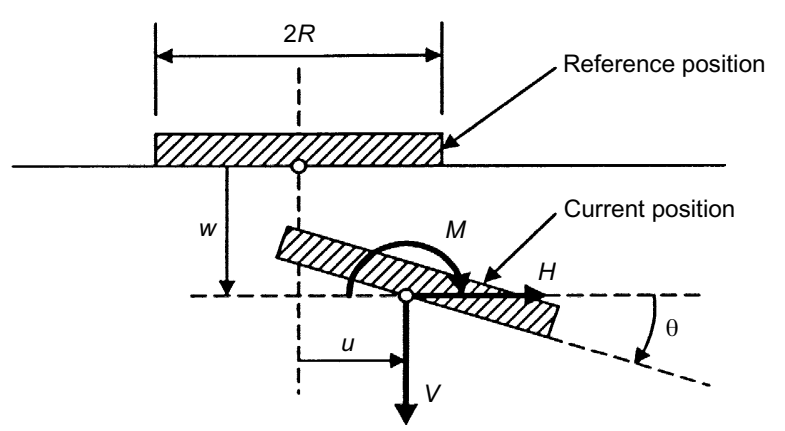

Fig. 1. Sign convention adopted for loads and displacements (after Butterfield et al., 1997) 


$$
\begin{aligned}
& f(V, M / 2 R, H)=\left(\frac{H}{h_{0} V_{0}}\right)^{2}+\left(\frac{M / 2 R}{m_{0} V_{0}}\right)^{2} \\
& -\frac{2 a H M / 2 R}{h_{0} m_{0} V_{0}^{2}}-\left[\frac{\left(\beta_{1}+\beta_{2}\right)^{\left(\beta_{1}+\beta_{2}\right)}}{\beta_{1}^{\beta_{1}} \beta_{2}^{\beta_{2}}}\right]^{2}\left(\frac{V}{V_{0}}\right)^{2 \beta_{1}} \\
& \times\left(1-\frac{V}{V_{0}}\right)^{2 \beta_{2}}=0
\end{aligned}
$$

The size of the yield surface is determined by the point on the surface of maximum $V$ value, and is defined as $V_{0}$. Once the yield surface is established, any change of load within the surface results in elastic deformation. Plastic deformation results when the load state touches the surface.

(b) An empirical strain-hardening expression, known as the hardening law, to define the variation of the size of the yield surface. For most shallow foundation models the size of the yield surface is a function of the plastic component of vertical displacement. The shape of the yield surface is assumed constant; however, as the footing is pushed into the soil its size expands with the amount of plastic vertical displacement $\left(w_{\mathrm{p}}\right)$. A functional form that fits the carbonate sand experimental data for pure vertical penetration is:

$$
V_{0}=\frac{c w_{\mathrm{p}}+k_{2} w_{\mathrm{p}}^{2}}{k_{1}+w_{\mathrm{p}}}
$$

Byrne \& Houlsby (2001) observed that, for the carbonate sand tests, the hardening also depended on horizontal movement and rotation as well as on vertical movement. They suggest that $w_{\mathrm{p}}$ in equation (2) could be replaced by $x_{\mathrm{p}}=w_{\mathrm{p}}+C_{1}\left|u_{\mathrm{p}}\right|+C_{2}\left|2 R \theta_{p}\right|$. Therefore hardening becomes a function not only of the vertical plastic displacement, but also of the plastic horizontal and rotational displacements. It was found that better simulation of the experimental data could be achieved with this modification. Byrne \& Houlsby (2001) suggested values of 0.5 for $C_{1}$ and 0.2 for $C_{2}$ as well as some minor changes to parameter values (see Table 1) to give an improved modelling of the data. It should be noted that for most practical situations this additional complexity may not be necessary, and that the original hardening mechanism will suffice.

(c) A model for elastic load-displacement behaviour within the yield surface. The coefficients are as defined by Bell (1991):

$$
\left(\begin{array}{c}
\delta V \\
\delta M / 2 R \\
\delta H
\end{array}\right)=2 G R\left[\begin{array}{ccc}
k_{\mathrm{v}} & 0 & 0 \\
0 & k_{\mathrm{m}} & k_{\mathrm{c}} \\
0 & k_{\mathrm{c}} & k_{\mathrm{h}}
\end{array}\right]\left(\begin{array}{c}
\delta w^{\mathrm{e}} \\
2 R \delta \theta^{\mathrm{e}} \\
\delta u^{\mathrm{e}}
\end{array}\right)
$$

(d) A suitable flow rule (usually defined by a plastic potential surface) to allow prediction of the footing displacements during yield:

$$
\begin{aligned}
g(V, M / 2 R, H)= & \left(\frac{H}{\alpha_{\mathrm{h}} h_{0} V_{0}^{\prime}}\right)^{2}+\left(\frac{M / 2 R}{\alpha_{\mathrm{m}} m_{0} V_{0}^{\prime}}\right)^{2} \\
& -2 a \frac{H M / 2 R}{\alpha_{\mathrm{h}} \alpha_{\mathrm{m}} h_{0} m_{0} V_{0}^{\prime 2}} \\
& -\left[\frac{\left(\beta_{3}+\beta_{4}\right)^{\left(\beta_{3}+\beta_{4}\right)}}{\left(\beta_{3}\right)^{\beta_{3}}\left(\beta_{4}\right)^{\beta_{4}}}\right]^{2}\left(\frac{V}{V_{0}^{\prime}}\right)^{2 \beta_{3}} \\
& \times\left(1-\frac{V}{V_{0}^{\prime}}\right)^{2 \beta_{4}}=0
\end{aligned}
$$

Here the association factors $\alpha_{\mathrm{h}}$ and $\alpha_{\mathrm{m}}$ are defined by the hyperbolic functions

$$
\begin{aligned}
& \alpha_{\mathrm{h}}=\frac{k^{\prime}+\alpha_{\mathrm{h} \infty}\left(u_{\mathrm{p}} / w_{\mathrm{p}}\right)}{k^{\prime}+\left(u_{\mathrm{p}} / w_{\mathrm{p}}\right)} \\
& \alpha_{\mathrm{m}}=\frac{k^{\prime}+\alpha_{\mathrm{m} \infty}\left(2 R \theta_{\mathrm{p}} / w_{\mathrm{p}}\right)}{k^{\prime}+\left(2 R \theta_{\mathrm{p}} / w_{\mathrm{p}}\right)}
\end{aligned}
$$

Notes on the development of the plastic potential

To model load-displacement behaviour, incremental plastic displacements at yield are used to define a suitable flow rule. To achieve this, the displacements were investigated on two planes: the $M / 2 R V_{0}: H / V_{0}$ plane and the deviatoric/ normal planes $\left(H / V_{0}: V / V_{0}\right.$ and $\left.M / 2 R V_{0}: V / V_{0}\right)$. If associated flow is assumed in the $M / 2 R V_{0}: H / V_{0}$ plane, then $\alpha_{\mathrm{h}}=\alpha_{\mathrm{m}}=1$ and the theoretical change in horizontal displacement and rotation can be derived from the yield surface as

$$
\begin{aligned}
& \delta u_{\mathrm{p}}=\lambda \frac{\partial f}{\partial H}=\lambda\left(\frac{2 H}{h_{0}^{2} V_{0}^{2}}-\frac{2 a M / 2 R}{h_{0} m_{0} V_{0}^{2}}\right) \\
& 2 R \delta \theta_{\mathrm{p}}=\lambda \frac{\partial f}{\partial(M / 2 R)}=\lambda\left(\frac{2 M / 2 R}{m_{0}^{2} V_{0}^{2}}-\frac{2 a H}{h_{0} m_{0} V_{0}^{2}}\right)
\end{aligned}
$$

where $\lambda$ is a multiplier that can be derived from the condition of continuity with the strain-hardening law. The ratio of plastic strain rates can therefore be written in terms of the current load state as

$$
\frac{\delta u_{\mathrm{p}}}{2 R \delta \theta_{\mathrm{p}}}=\frac{H 2 R\left(m_{0} / h_{0}\right)-a M}{M\left(h_{0} / m_{0}\right)-a H 2 R} .
$$

The incremental experimental plastic displacement ratios for the four swipe tests and four constant- $V$ tests conducted by Byrne \& Houlsby (2001) have been plotted against their load state in Fig. 2. In a swipe test the footing is displaced horizontally and/or rotated without any further displacement. Where as in the Constant- $V$ test the footing is horizontally displaced and/or rotated while maintaining the vertical load. The theoretical associated flow curve, equation (9), is also shown, and associated flow can be seen as a reasonable assumption in this plane.

Associated flow was not found to be valid in the $H / V_{0}: V / V_{0}$ and $M / 2 R V_{0}: V / V_{0}$ planes, with the associated flow rule underpredicting the vertical displacements. This is best shown by defining a general deviator force $Q$ as

$$
Q^{2}=\left(\frac{H}{h_{0}}\right)^{2}+\left(\frac{M / 2 R}{m_{0}}\right)^{2}-\frac{2 a H M / 2 R}{h_{0} m_{0}}
$$

According to plasticity theory the plastic displacements conjugate to $Q$ are therefore

$$
\delta q_{\mathrm{p}}=\lambda \frac{\partial f}{\partial Q}=\lambda 2 Q
$$

Combining equations (7), (8), (10) and (11), $\delta q_{\mathrm{p}}$ can be written in terms of horizontal displacements and moment rotations as

$$
\begin{aligned}
\delta q_{\mathrm{p}}^{2} & =\frac{1}{1-a^{2}} \\
& \times\left[\left(h_{0} d u_{\mathrm{p}}\right)^{2}+\left(m_{0} 2 R d \theta_{\mathrm{p}}\right)^{2}+2 a\left(h_{0} d u_{\mathrm{p}}\right)\left(m_{0} 2 R d \theta_{\mathrm{p}}\right)\right] .
\end{aligned}
$$

In Fig. 3, the angle of the force ratio $\tan ^{-1}(Q / V)$ against the angle of the displacement ratio $\tan ^{-1}\left(\delta q_{\mathrm{p}} / \delta w_{\mathrm{p}}\right)$ (calculated using equation (12)) for the four constant $V$ and four radial displacement tests conducted by Byrne \& Houlsby (2001) have been shown. In a radial displacement test the 
Table 1. Recommend values of Model $\mathrm{C}$ parameters for uncemented loose carbonate sand

\begin{tabular}{|c|c|c|c|c|c|}
\hline \multirow{3}{*}{$\begin{array}{l}\text { Constant } \\
\\
R \\
\end{array}$} & \multirow{3}{*}{$\begin{array}{c}\text { Dimension } \\
\\
\mathrm{L}\end{array}$} & \multirow[t]{2}{*}{ Explanation } & \multicolumn{2}{|c|}{ Typical values } & \multirow[t]{2}{*}{ Notes } \\
\hline & & & $\begin{array}{l}\text { Using } w_{\mathrm{p}} \text { in } \\
\text { eqn }(2)\end{array}$ & $\begin{array}{l}\text { Using } x_{\mathrm{p}} \text { in } \\
\text { eqn }(2)\end{array}$ & \\
\hline & & Footing radius & \multicolumn{2}{|c|}{ (Various) } & \\
\hline$\gamma$ & $\mathrm{F} / \mathrm{L}^{3}$ & Unit weight of soil & \multicolumn{2}{|c|}{$10 \mathrm{kN} / \mathrm{m}^{3}$} & $9.32 \mathrm{kN} / \mathrm{m}^{3}$ used in simulations \\
\hline $\bar{G}$ & $\mathrm{~F} / \mathrm{L}^{2}$ & Representative shear modulus & \multicolumn{2}{|c|}{ (Various) } & $\begin{array}{l}\text { See Cassidy (1999) and Cassidy et al. (2002) for } \\
\text { calculation method based on non-dimensionalised } \\
\text { factors. } G=11 \cdot 3 \mathrm{MPa} \text { used in simulations }\end{array}$ \\
\hline $\begin{array}{l}k_{\mathrm{v}} \\
k_{\mathrm{h}} \\
k_{\mathrm{m}} \\
k_{\mathrm{c}}\end{array}$ & $\begin{array}{l}- \\
- \\
- \\
-\end{array}$ & $\begin{array}{l}\text { Elastic stiffness factor (vertical) } \\
\text { Elastic stiffness factor (horizontal) } \\
\text { Elastic stiffness factor (moment) } \\
\text { Elastic stiffness factor (horizontal/moment coupling) }\end{array}$ & \multicolumn{2}{|c|}{$\begin{array}{l}2 \cdot 65 \\
2 \cdot 3 \\
0 \cdot 46 \\
-0 \cdot 14\end{array}$} & As defined in Bell (1991) \\
\hline$h_{0}$ & - & Dimension of yield surface (horizontal) & $0 \cdot 154$ & $0 \cdot 1505$ & Maximum value of $H / V_{0}$ on $M=0$ \\
\hline$\overline{m_{0}}$ & - & Dimension of yield surface (moment) & $0 \cdot 094$ & $0 \cdot 089$ & Maximum value of $M / 2 R V_{0}$ on $H=0$ \\
\hline$a$ & - & Eccentricity of yield surface & $-0 \cdot 25$ & $-0 \cdot 30$ & $-1.0<a<1.0$ \\
\hline $\begin{array}{l}\beta_{1} \\
\beta_{2}\end{array}$ & $\begin{array}{l}- \\
-\end{array}$ & $\begin{array}{l}\text { Curvature factor for yield surface (low stress) } \\
\text { Curvature factor for yield surface (high stress) }\end{array}$ & $\begin{array}{l}0 \cdot 82 \\
0 \cdot 82\end{array}$ & $\begin{array}{l}0 \cdot 75 \\
0 \cdot 75\end{array}$ & $\begin{array}{l}\beta_{1} \leqslant 1 \cdot 0, \beta_{2} \leqslant 1 \cdot 0 \\
\beta_{1}=\beta_{2}=1 \text { gives parabolic section }\end{array}$ \\
\hline $\begin{array}{l}\beta_{3} \\
\beta_{4} \\
\end{array}$ & $\begin{array}{l}- \\
- \\
\end{array}$ & $\begin{array}{l}\text { Curvature factor for plastic potential (low stress) } \\
\text { Curvature factor for plastic potential (high stress) } \\
\end{array}$ & \multicolumn{2}{|c|}{$\begin{array}{l}0 \cdot 82 \\
0 \cdot 82\end{array}$} & $\beta_{3} \leqslant 1 \cdot 0, \beta_{4} \leqslant 1 \cdot 0$ \\
\hline$\alpha_{\mathrm{h}}$ & - & Association factor (horizontal) & \multicolumn{2}{|c|}{$1 \cdot 0-3 \cdot 25$} & Variation according to equation (5) and $\alpha_{\mathrm{h} \infty}=3.25$ \\
\hline$\alpha_{\mathrm{m}}$ & - & Association factor (moment) & \multicolumn{2}{|c|}{$1 \cdot 0-2 \cdot 6$} & Variation according to equation (6) and $\alpha_{m \infty}=2.6$ \\
\hline$k^{\prime}$ & - & Rate of change in association factors & \multicolumn{2}{|c|}{$0 \cdot 275$} & Equations (5) and (6) \\
\hline $\begin{array}{l}c \\
k_{1} \\
k_{2}\end{array}$ & $\begin{array}{c}\mathrm{F} \\
\mathrm{L} \\
\mathrm{F} / \mathrm{L}\end{array}$ & Hardening law parameters & \multicolumn{2}{|c|}{$\begin{array}{r}700 \\
50 \\
48\end{array}$} & $\begin{array}{l}\text { Parametric values providing the best fit to the } \\
\text { experimental data of Byrne \& Houlsby (2001) } \\
\text { using equation (2) }\end{array}$ \\
\hline $\begin{array}{l}C_{1} \\
C_{2}\end{array}$ & $\begin{array}{l}- \\
-\end{array}$ & $\begin{array}{l}\text { Proportions of horizontal and rotational plastic } \\
\text { movements considered in hardening law }\end{array}$ & $\begin{array}{l}\text { n.a. } \\
\text { n.a. }\end{array}$ & $\begin{array}{l}0 \cdot 5 \\
0 \cdot 2\end{array}$ & As recommended in Byrne \& Houlsby (2001) \\
\hline
\end{tabular}




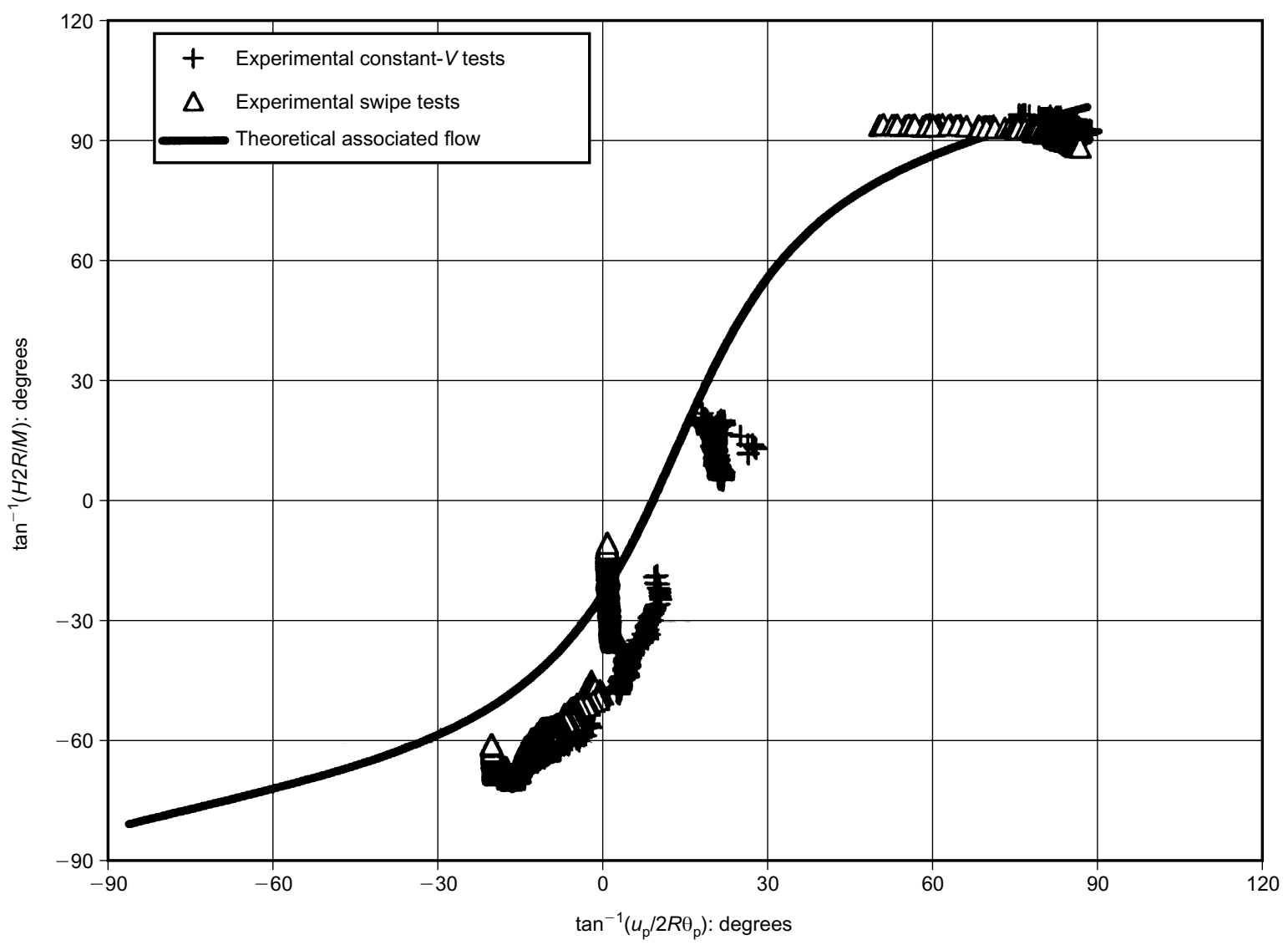

Fig. 2. Incremental plastic displacement ratios in the $M / 2 R: H$ plane

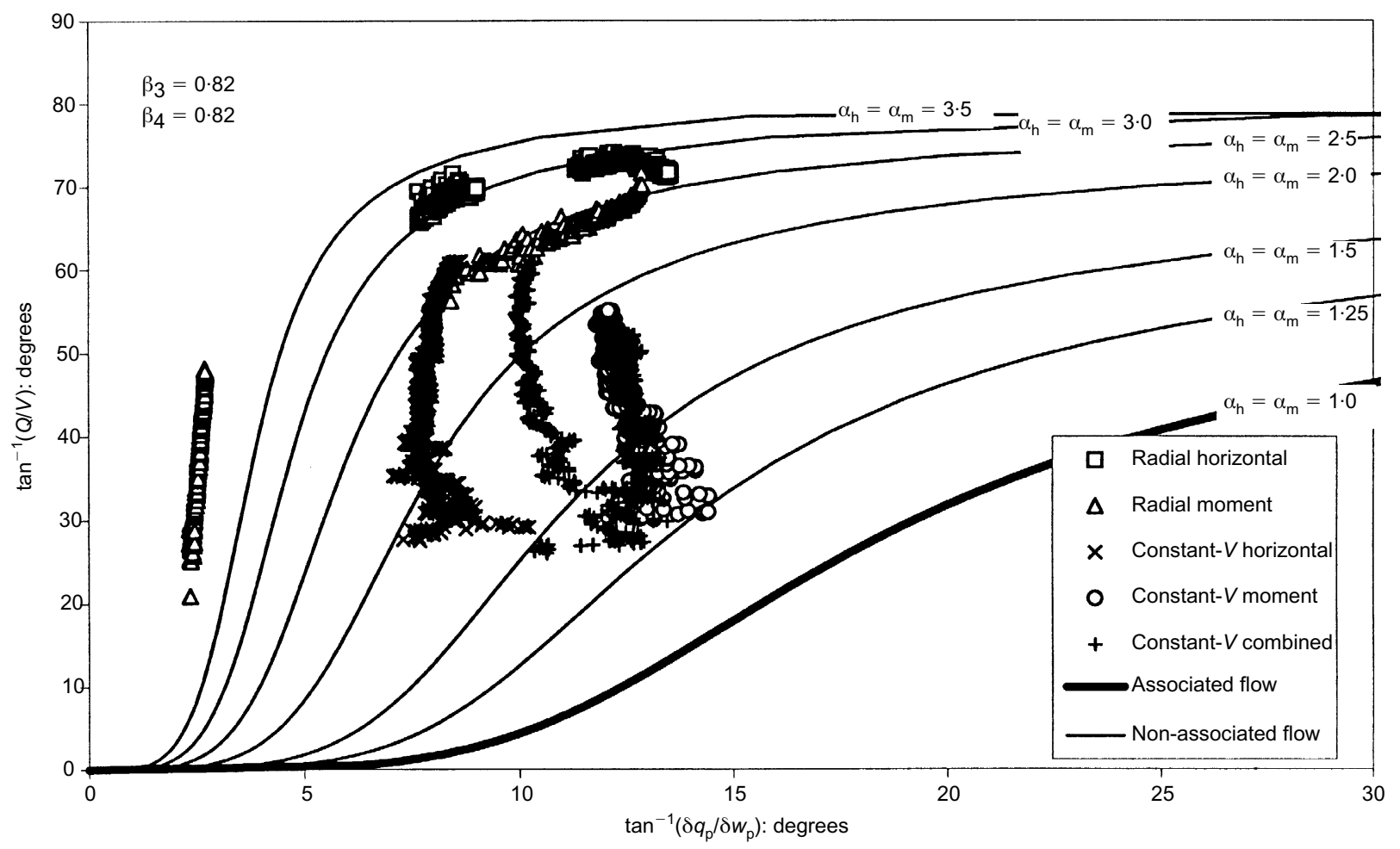

Fig. 3. Comparison of experimental displacement directions and theoretical predictions in the deviatoric planes 
footing is probed from the surface at a constant ratio of horizontal and/or rotational displacement to vertical displacement. These results can now be compared with theoretical estimates. The theoretical associated flow curve is also presented in Fig. 3: as expected, it substantially overestimates $\delta q_{\mathrm{p}} / \delta w_{\mathrm{p}}$ for all force ratios. By systematically increasing $\alpha_{\mathrm{h}}$ and $\alpha_{\mathrm{m}}$ in the plastic potential of equation (4) the degree of non-association can be compared with the experimental results. It can be seen in Fig. 3 that values between 1.5 and 3.0 correspond to sections of the results, but no single value fits all.

As was the case for the silica sand, the experimental data can be fitted well only if $\alpha_{\mathrm{h}}$ and $\alpha_{\mathrm{m}}$ are themselves variable. Hyperbolic functions of plastic displacement histories have been used to vary the plastic potential shape (equations (5) and (6)). Variation occurs as a result of the differences in test type (radial displacement and constant vertical load) and in horizontal, moment and combined horizontal/moment loading. Further details of this approach can be found in Cassidy (1999).

\section{MODELLING OF EXPERIMENTS}

To investigate the capability of the modified Model C to predict footing behaviour, numerical simulations were carried out for a number of representative experiments. The experiments reported by Byrne \& Houlsby (2001) involve loading of a $150 \mathrm{~mm}$ diameter footing on uncemented loose carbonate sand. These are the same tests used to estimate the model parameters shown in Table 1, so the quality of the fit will of course be good. However, the purpose here is to highlight the model's overall predictive capabilities on this sand type, and its ability to capture the salient features of the original data. The minor fluctuations associated with experimental measurements have been removed and the input paths idealised for the numerical simulations.

\section{Vertical penetration test}

Figure 4 shows the experimental results for a vertical penetration test and a simulation of this same test in which the measured displacement is taken as input, and the vertical load is calculated. The modified Model $\mathrm{C}$ gives loads that accurately represent the original test, and this is principally a test of the chosen strain-hardening law.

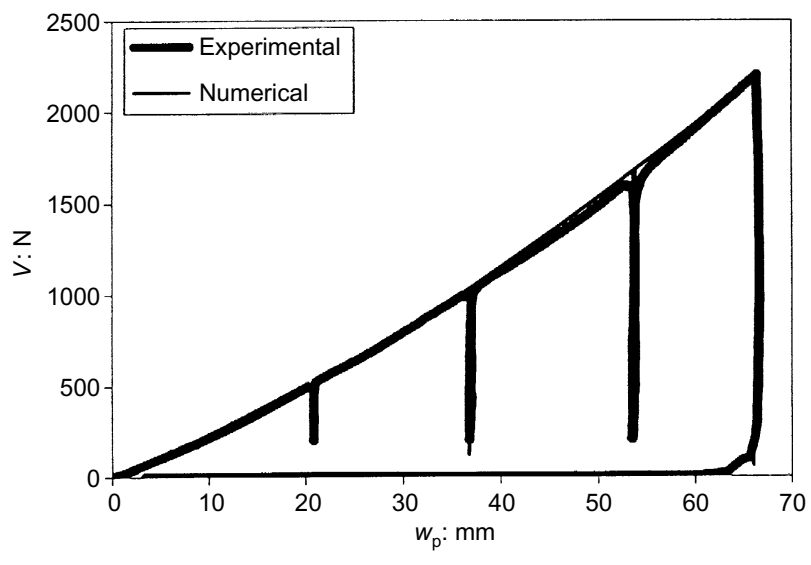

Fig. 4. Retrospective simulation of vertical penetration test (fit of hardening law)

Horizontal and moment swipe tests

In a swipe test the footing is load controlled in the vertical direction until it reaches a prescribed load, in this case $V \approx 1600 \mathrm{~N}$. Horizontal displacement or rotation is then applied to the footing with no further vertical displacement. The trace in $V: M: H$ space corresponds to a track along the yield surface, appropriate for that embedment.

Figures 5(a) and 6(a) present respectively the pure horizontal and pure moment swipes starting at $V=1600 \mathrm{~N}$. The modified Model $\mathrm{C}$ simulates the magnitude of the peak loads well, with a slight overprediction for the pure horizontal case and a slight underprediction for pure moment. Though not shown here, the yield surface shape is a best fit to not only these two, but also other combined horizontal/moment load swipes. Therefore the simulations shown in Figs 5 and 6 represent a compromise fit to the yield surface. Figs 5(b) and 6(b) show the load-displacement response. In both cases the amount of displacement predicted before the peak load is accurately modelled. The stiffness of this part of the footing response is sensitive to the value of the shear modulus chosen. Tan (1990) defined a parallel point analogous to a critical state where, for continuing deviatoric movements at a constant vertical displacement, there was no change in the load state on the footing. The model locates the parallel point at a slightly lower vertical load in the moment case and at a slightly higher vertical load in the horizontal-again, a good compromise. This affects the load-displacement simulation post peak, but both simulations adequately represent the general trend.

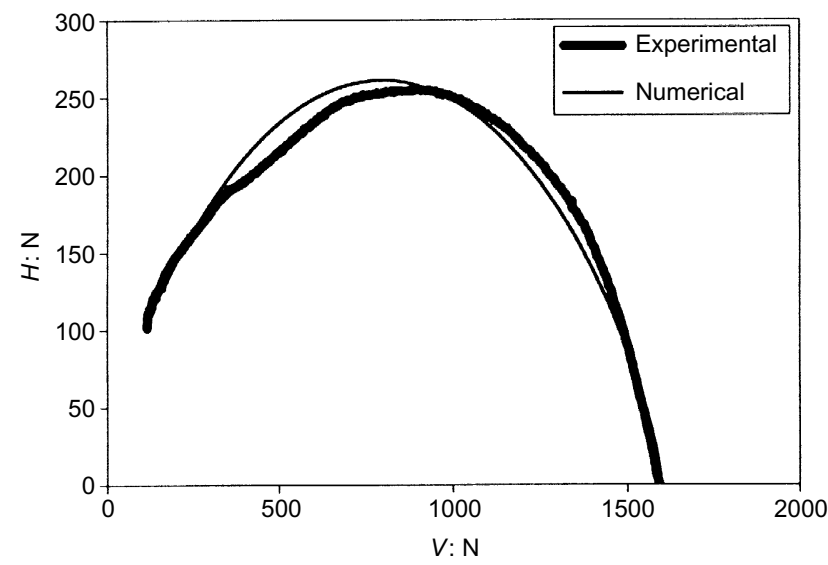

(a)

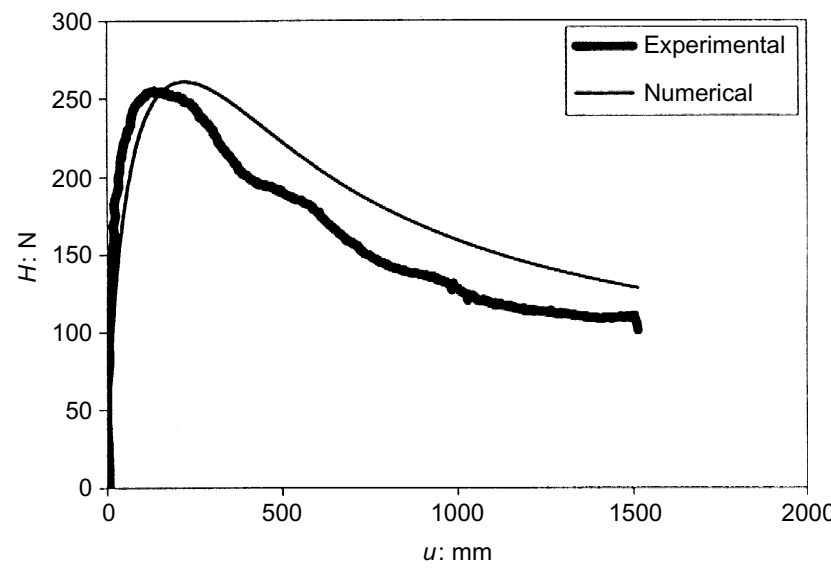

(b)

Fig. 5. Retrospective simulation of horizontal swipe test: (a) pure horizontal swipe; (b) load-displacement response 


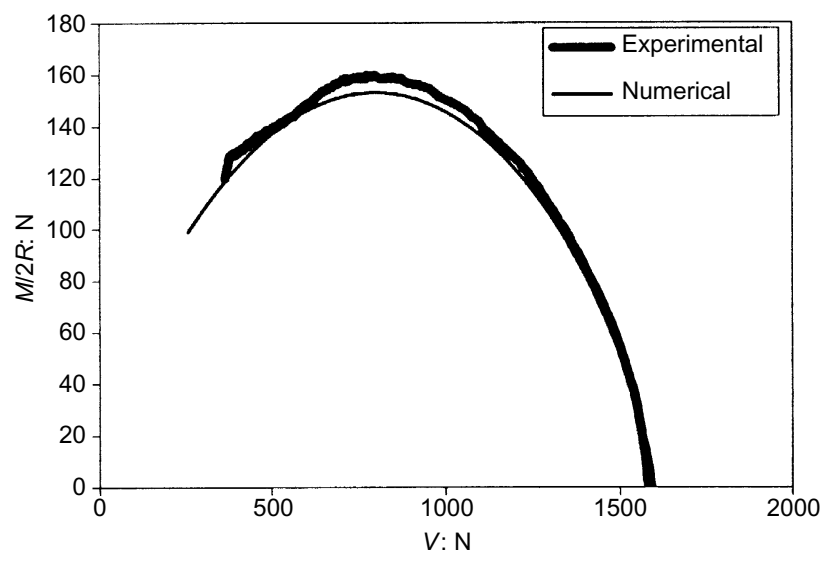

(a)

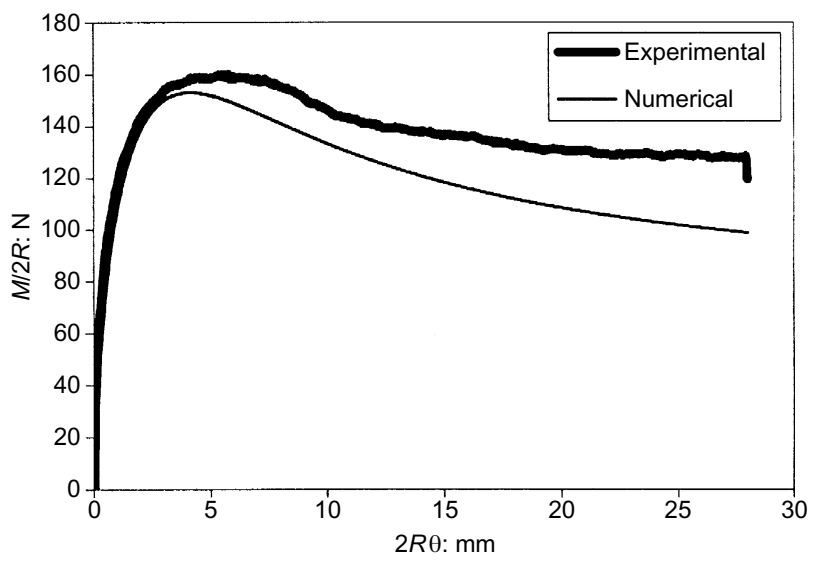

(b)

Fig. 6. Retrospective simulation of moment swipe test: (a) pure moment swipe; (b) load-displacement response

\section{Constant vertical load tests}

The constant- $V$ tests as shown in Figs 7 and 8 are simulated with full load control to $V \approx 1600 \mathrm{~N}$. The vertical load is then kept constant while horizontal and moment excursions are executed using displacement control. On loose carbonate sand the constant- $V$ tests involve the continual expansion of the yield surface. The horizontal experimental data show a stiff initial response to $H \approx 120 \mathrm{~N}$ followed by a softer hardening response, as shown in Fig. 7. The moment data, shown in Fig. 8, follow similar trends.

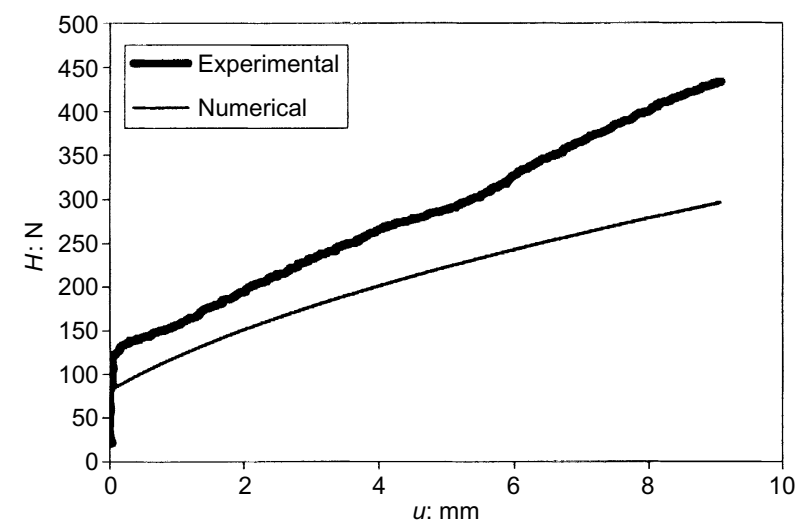

(a)

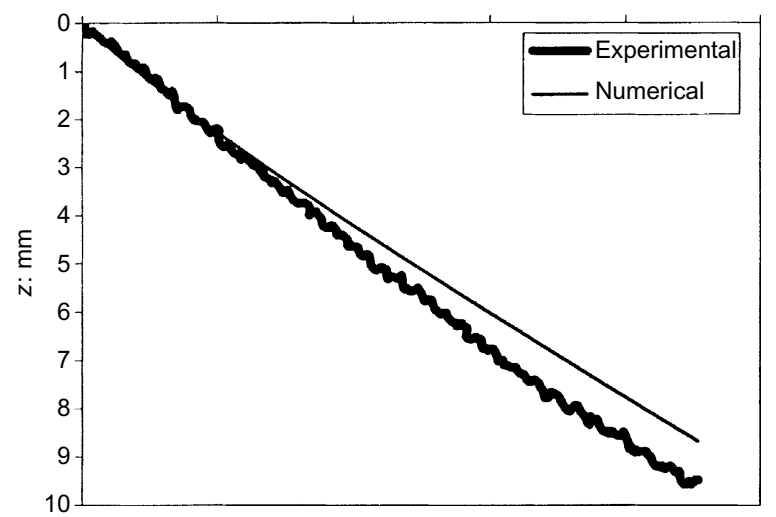

(b)

Fig. 7. Retrospective simulation of the horizontal constant- $V$ test $\left(V \approx 1600 \mathrm{~N}\right.$ and $\left.\tan ^{-1}(2 R \delta \theta / \delta u)=1 \cdot 2^{\circ}\right)$

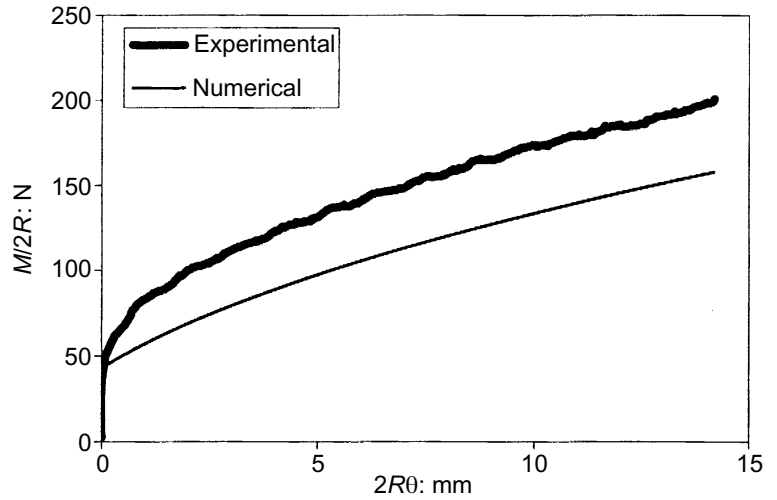

(a)

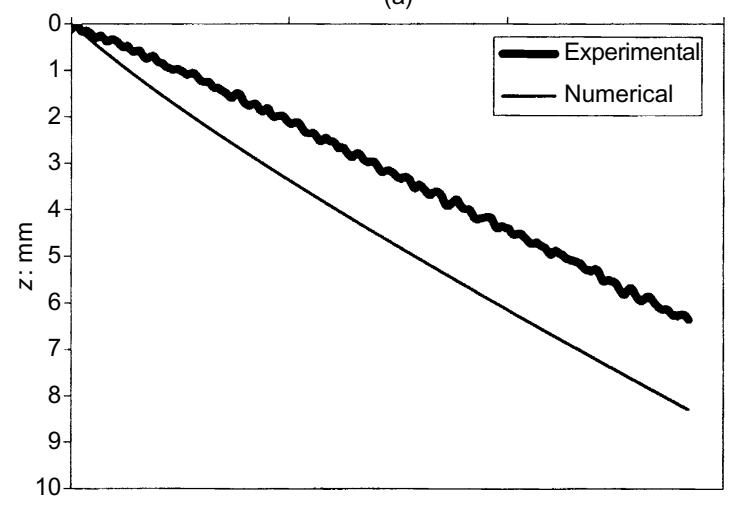

(b)

Fig. 8. Retrospective simulation of the moment constant- $V$ test $\left(V \approx 1600 \mathrm{~N}\right.$ and $\left.\tan ^{-1}(2 R \delta \theta / \delta u)=87.9^{\circ}\right)$

Figures 7(a) and 8(a) show that modified Model C models expanding yield surfaces reasonably well. However, the simulations are underpredicting the experimental horizontal and moment loads. Figs 7(b) and 8(b) show that the flow rule satisfactorily predicts the vertical displacements when compared with the horizontal or rotational displacements, which are part of the input. Fig. 8(b) shows a slight overprediction in vertical displacements, indicating that for this case the slope of the plastic potential is too high. However, with Fig. 7(b) showing a slight underprediction, the flow rule is predicting balanced results. With the flow rule giving good prediction of vertical displacement, the underprediction of the horizontal and moment loads is probably due to 
inadequately representing the contribution of plastic horizontal displacements and rotations to the expansion of the yield surface. Increasing constants $C_{1}$ and $C_{2}$ in equation (3) could improve this, but this would affect the swipe and radial displacement tests (where reasonable prediction of the horizontal and moment loads is achieved).

\section{Radial displacement tests}

Constant gradients of horizontal to vertical and moment to vertical displacement were used as inputs to simulate horizontal and moment radial displacement tests. The resulting experimental horizontal and moment loads and modified Model C predictions are shown in Figs 9(a) and 10(a) respectively. The simulations are of a similar gradient and finish on approximately the same load combination, implying that the modified Model $\mathrm{C}$ flow rule is performing well. This is also shown in Fig. 9(b), where the horizontal load is seen to be increasing at a similar rate to the input horizontal displacement. Though finishing at the correct level, Fig. 10(b) shows modified Model $\mathrm{C}$ underpredicting the moment load during the initial stages of the radial displacement tests. Overall, the radial displacement tests are well represented.

\section{CONCLUSION}

A complete theoretical model has been described for the behaviour of rigid circular footings on loose carbonate sand. The model, which is expressed in terms of work-hardening

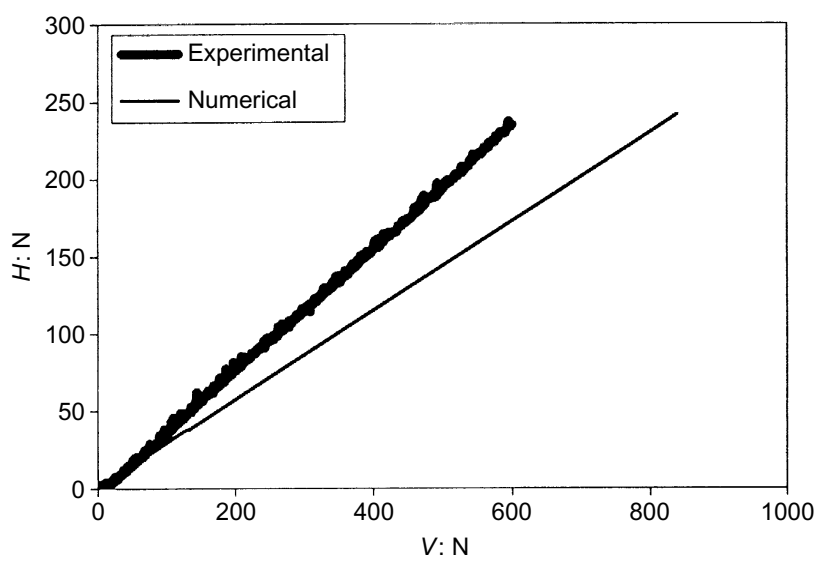

(a) plasticity theory, has been previously used to describe the behaviour of circular footings on dense silica sand by Houlsby \& Cassidy (2002). A series of specifically designed tests on loose carbonate sand (Byrne \& Houlsby, 2001) have been used to verify its suitability for this soil type and conditions. The model makes use of the force resultants and the corresponding displacements of the footing, and allows predictions of response to be made for any load or displacement combination. The suggested modifications to the original Model $\mathrm{C}$ result in excellent simulations of the experimental data.

\section{ACKNOWLEDGEMENTS}

The Centre for Offshore Foundation Systems was established and is funded under the Australian Government's Special Research Centres Program. The second author acknowledges the generous support from Magdalen College, Oxford.

\section{NOTATION}

$\begin{array}{cl}a & \text { eccentricity factor for yield surface } \\ c & \text { constant used in hardening law } \\ f & \text { yield surface } \\ g & \text { plastic potential } \\ G & \text { shear modulus } \\ h_{0} & \text { dimensionless size factor for yield surface } \\ H & \text { horizontal load }\end{array}$

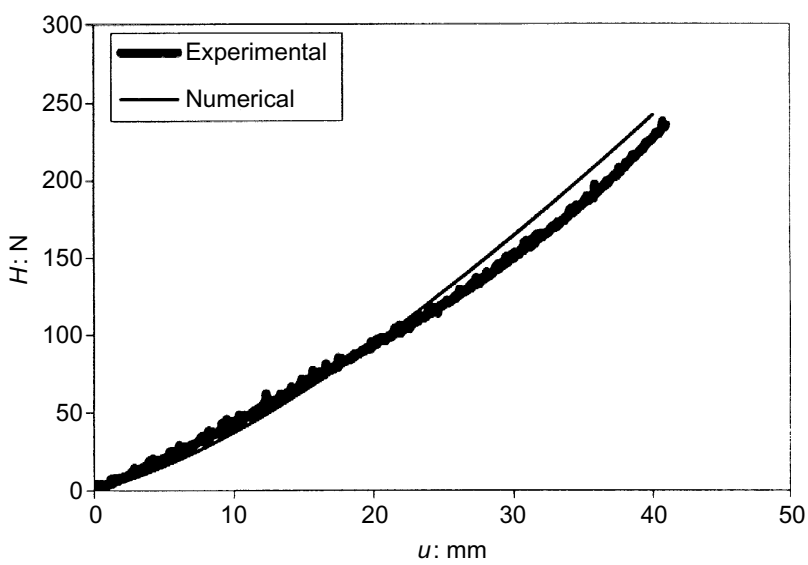

(b)

Fig. 9. Retrospective simulation of the horizontal radial displacement test $(\delta u / \delta w=0.997)$

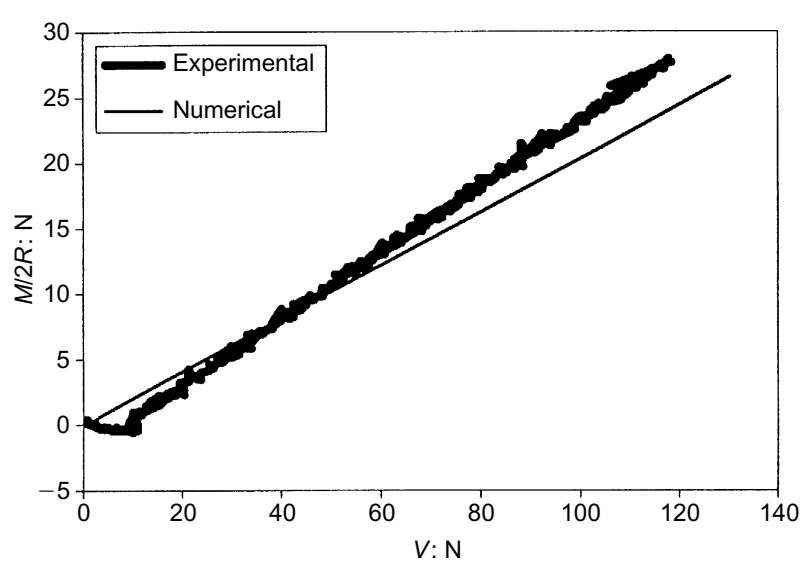

(a)

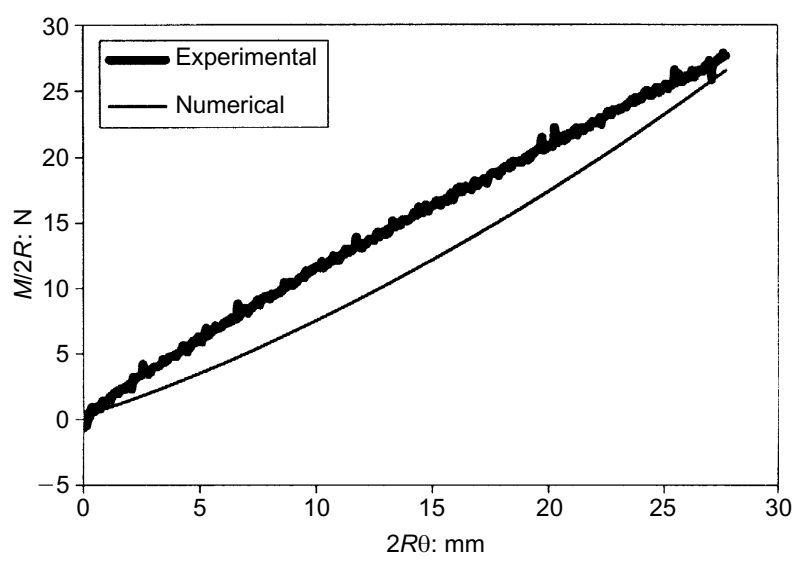

(b)

Fig. 10. Retrospective simulation of the moment radial displacement test $(2 R \delta \theta / \delta w=2 \cdot 356)$ 
$k^{\prime}$ constant in expression for association factors

$k_{\mathrm{v}}, k_{\mathrm{m}}, k_{\mathrm{h}}, k_{\mathrm{c}}$ elastic stiffness factors

$k_{1}, k_{2}$ stiffness factors used in hardening law

$m_{0}$ dimensionless size factor for yield surface

$M$ moment

$R$ foundation radius

$u$ horizontal displacement

$V$ vertical load

$V_{0}$ dimension of yield surface in v-direction (maximum past vertical load for pure vertical loading)

$V_{0}^{\prime} \quad$ dummy size parameter for plastic potential

$w$ vertical displacement

$x$ factored vertical, horizontal and rotational displacement

$\alpha_{\mathrm{m}}, \alpha_{\mathrm{h}}$ association factors

$\alpha_{\mathrm{m} \infty}, \alpha_{\mathrm{h} \infty}$ limiting values of association factors

$\beta_{1}, \beta_{2}$ shaping factors for yield surface

$\beta_{3}, \beta_{4}$ shaping factors for plastic potential

$\theta$ rotation

Subscripts and superscripts

e elastic

p plastic

\section{REFERENCES}

Bell, R. W. (1991). The analysis of offshore foundations subjected to combined loading. MSc thesis, Oxford University.

Butterfield, R., Houlsby, G. T. \& Gottardi, G. (1997). Standardized sign conventions and notation for generally loaded foundations. Géotechnique 47, No. 5, 1051-1054.

Byrne, B. W. (2000). Investigations of suction caissons in dense sand. DPhil thesis, University of Oxford.

Byrne, B. W. \& Houlsby, G. T. (1998). Model testing of circular flat footings on uncemented loose carbonate sand: experimental data. Oxford University Report No. OUEL 2192/98.

Byrne, B. W. and Houlsby, G. T. (2001). Observations of footing behaviour on loose carbonate sands. Géotechnique 51, No. 5, 463-466.

Cassidy, M. J. (1999). Non-linear analysis of jack-up structures subjected to random waves. DPhil thesis, University of Oxford.

Cassidy, M. J., Houlsby, G. T., Hoyle, M. \& Marcom, M. (2002). Determining appropriate stiffness levels for spudcan foundations using jack-up case records. Proc. 21st Int. Conf. on Offshore Mechanics and Arctic Engineering (OMAE), Oslo, OMAE200228085.

Gottardi, G. \& Butterfield, R. (1993). On the bearing capacity of surface footings on sand under general planar loads. Soils Found. 33, No. 3, 68-79.

Gottardi, G. \& Butterfield, R. (1995). The displacement of a model rigid surface footing on dense sand under general planar loading. Soils Found. 35, No. 3, 71-82.

Gottardi, G., Houlsby, G. T. \& Butterfield, R. (1999). The plastic response of circular footings on sand under general planar loading. Géotechnique 49, No. 4, 453-470.

Houlsby, G. T. \& Cassidy, M. J. (2002). A plasticity model for the behaviour of footings on sand under combined loading. Géotechnique 52, No. 2, 117-129.

Martin, C. M. \& Houlsby, G. T. (2000). Combined loading of spudcan foundations on clay: laboratory tests. Géotechnique 50, No. 4, 325-338.

Martin, C. M. \& Houlsby, G. T. (2001). Combined loading of spudcan foundations on clay: numerical modelling. Géotechnique 51, No. 8, 687-700.

Nova, R. \& Montrasio, L. (1991). Settlements of shallow foundations on sand. Géotechnique 41, No. 2, 243-256.

Schotmann, G. J. M. (1989). The effects of displacements on the stability of jackup spudcan foundations. Proc. 21st Offshore Technology Conf., Houston, OTC 6026.

Tan, F. S. C. (1990). Centrifuge and numerical modelling of conical footings on sand. $\mathrm{PhD}$ thesis, Cambridge University. 